\title{
Anaesthesia and Rett syndrome: a case report
}

Rett syndrome is a neurological disorder of females characterized by dementia, autism. movement disorders and an abnormality of respiratory control.

A 14-year-old girl with Rett Syndrome undenwent spinal fusion surgery under general anaesthesia. No exacerbation of the respiratory control defect with surgery and anaesthesia was observed. Hypothermia, ongoing blood loss and a normal anion gap acidosis were encountered, but were not attributable to features of this disorder.

Rett syndrome is a progressive neurological discase found exclusively in females, characterized by dementia, autistic behaviour, stereotyped hand movements and an abnormality of respiratory control. ${ }^{1}$ We recently anaesthetized a patient who demonstrated most of the features of this disorder. Anaesthetic experience in patients with this disease has not previously been reported.

\section{Case report}

A 14-year-old white female with Rett Syndrome was scheduled for elective Harrington Rod spinal fusion for correction of a scoliosis curve of $58^{\circ}$, by the Cobb method, which had rapidly progressed despite bracing. On admission to the hospital initial examination by the attending anaesthetist revealed a pleasant looking, frail, red headed child displaying a great deal of hand wringing. She was unable to speak and sat supported in a wheelchair, totally dependent in all aspects of daily care.

Early history included term vaginal forceps delivery with normal Apgar scores. Birth weight was $3.5 \mathrm{~kg}$. She was reported to be smiling at 6 weeks, head holding at four months, sitting at ten months and feeding herself at one year. Between 12-18 months of age previously acquired speech and interest in surroundings were lost. She never crawled but learned to walk by age four with a

\section{Key words}

COMPLICATIONS; dementia; respiratory, apnoea; INHERITED DESEASE: Rett syndrome, anaesthesia; SYNDROME: Rett.

From the Department of Anaesthesia, University of Manitoba Children's Hospital, 840 Sherbrook St., Winnipeg, Manitoba R3A IS1.

Address correspondence to: Dr. C. Bachman. spastic hop. Communication was limited to pointing and crying. Formal assessment at age seven estimated development at the one-year level. Since that time thene have been small gains in social development but also deterioration of motor skills. Extensive investigations failed to provide a diagnosis until the diagnosis of Rett syndrome was recently recognized.

Previous general anaesthesia for diagnostic CT scan at six years of age had been uneventful. Seizures, present since age six, were well controlled with valproate. She had a weak non-productive cough. There was no history of recurrent pneumonia. Her parents had noted episodes of irregular breathing; these were most often during sleep and not associated with cyanosis.

On examination, she was $24 \mathrm{~kg}$, normotensive, afebrile and not distressed. Her head was small with the circumference less than the third percentile. The airway was normal apart from excessive secretions. A thoracic scoliosis was present. Auscultation of the heart and chest was unremarkable. The extremities were cool, without clubbing or cyanosis. Muscle mass was diminished, tone increased and reflexes were brisk.

Preoperative haemoglobin concentration was $129 \mathrm{~g} \cdot \mathrm{L}^{-1}$ and biochemistry was normal. The heart and lungs were normal on chest $x$-ray. The ECG was unremarkable. Lack of patient cooperation prevented pulmonary function testing.

The child was quiet on arrival in the operating room without premedication. Monitors were established and anaesthesia induced by mask with halothane and nitrous oxide. The trachea was intubated with a $6.0 \mathrm{~mm}$ oral tracheal tube following administration of pancuronium $2.5 \mathrm{mg}$. The patient was placed prone on a Relton Hall frame. Ventilation was controlled using a circle system and Ohio ventilator. Anaesthesia was maintained with $\mathrm{N}_{2} \mathrm{O}_{2} \mathrm{~L} \cdot \mathrm{min}^{-1}, \mathrm{O}_{2} 1.6 \mathrm{~L} \cdot \mathrm{min}^{-1}$, isoflurane $0.5-1.0$ per cent and $7 \mathrm{mg}$ morphine. Monitoring included nasal pharangeal temperature, intra-arterial catheter, foley catheter, pulse oximeter, end-tidal carbon dioxide, inspired-expired isoflurane and oxygen concentrations.

Intraoperatively her temperature fell to $33.5^{\circ} \mathrm{C}$ within two hours despite warming of the room to $26^{\circ} \mathrm{C}$, warming the IV solution and heating and humidifying the inspired gases. Estimated blood loss of $1300 \mathrm{ml}$ was replaced with packed cells and normal saline. Haemodynamic variables and arterial blood gases were stable. 
At the completion of surgery the trachea was reintubated with a nasal tracheal tube and the patient was transferred to the ICU without awakening. Mechanical ventilation was continued. Normothermia was achieved following three hours of surface warming. In the first ten hours following surgery, $300 \mathrm{ml}$ packed blood cells, 250 $\mathrm{ml}$ fresh frozen plasma and $1.5 \mathrm{~L}$ crystalloid, primarily normal saline, were administered to manage ongoing blood loss and maintain haemodynamic stability. An arterial blood gas measurement two hours postoperatively during controlled ventilation $\left(\mathrm{FIO}_{2} \quad 0.4\right)$ showed $\mathrm{PaO}_{2}=108 \mathrm{mmHg}, \mathrm{PCO}_{2}=37 \mathrm{mmHg}, \mathrm{pH}=$ $7.29, \mathrm{HCO}_{3}=17.6$ and base excess -8.3 . The metabolic acidosis was associated with a normal anion gap and corrected as volume status normalized. The lungs were ventilated overnight and the patient maintained satisfactory arterial blood gases after extubation. Post-extubation, pulse oximetry monitoring for six hours in the ICU did not detect any episodes of desaturation. She was discharged home on the tenth postoperative day.

\section{Discussion}

In 1966 Rett described a syndrome of progressive deterioration of higher brain function occurring only in girls. ${ }^{2}$ This illness had remarkably consistent clinical features including a period of normal development for the first 4-18 months followed by rapid developmental regression leading to dementia associated with severe autistic behaviour. Acquired elements of language were lost, purposeful movement of the hands was lost and stereotypic handwashing movements were exhibited. ${ }^{1}$ Axial hypotonia and limb spasticity frequently develop. Various movement disorders were exhibited, including choreoathetosis, dystonia, myoclonic jerk and stereotypic automatism. ${ }^{1,3}$

In the chronic phase there is diffuse and progressive muscle wasting. Growth stagnation occurs involving weight, stature and, in particular, microcephaly. Survival beyond age 30 has been reported, but is not common. With age advancing into the teens most are functionally restricted to a wheelchair. ${ }^{1}$

Although described over 20 years ago, widespread awareness of this syndrome is very recent. Prevalence studies now indicate that it is not a rare phenomenon. It is estimated that among the population of severely retarded females the prevalence may be as high as 25 per cent. ${ }^{4}$

To date, no studies have clarified the pathogenesis or cause of this disorder, and no diagnostic laboratory test has been identified. The diagnosis is made by exclusion of other causes of developmental delay and by compatible clinical features. The sex distribution is inconsistent with an acquired disease. The hypothesis of an $x$-linked dominant mutation which is lethal for males is consistent with genetic data but hard to confirm as affected girls are unlikely to bear children.

Neurological, respiratory, cardiovascular and metabolic features of this disorder present potential anaesthetic problems. Considerations arising from neuromuscular involvement include lack of cooperation, control of seizures and limb movements, positioning and selection of muscle relaxants. Medical manipulations or introduction to the operating room may precipitate behavioural problems which can be associated with respiratory irregularities. ${ }^{5}$ Heavy preoperative sedation may prevent such a response but could have undesirable side effects. Music is said to have a calming effect in patients with Rett syndrome and achieve a temporary cessation of stereotypic movements. ${ }^{6}$ Familiar music accompanying these children may be useful before induction of anaesthesia. The muscle wasting and altered muscle tone demand close attention to proper positioning. Cooperman ${ }^{7}$ has described increases in serum potassium concentration following succinylcholine in patients with various neuromuscular disorders. For this reason we used a non-depolarizing muscle relaxant and selected pancuronium for its cardiovascular stimulating effects.

These children may be at risk of recurrent aspiration and impaired respiratory function from muscle weakness and thoracic deformity. In addition, abnormal patterns of respiration are characteristic. Polygraphic studies reveal that breathing is stable and regular during sleep. Wakefulness is associated with periods of disorganized, ineffective respiratory efforts, frequently mixed with apnoea. 5,8 Episodes of irregular breathing resulted in significant arterial oxygen desaturation and loss of consciousness during severe episodes. ${ }^{9}$ An impairment of the behavioural control system of breathing which is considered to be a forebrain function has been suggested. ${ }^{5}$ The rapid development of desaturation may be due to the high expiratory position of the diaphragm during apnoea. Other investigators have demonstrated evidence of upper airway obstruction suggesting a combined central and obstructive role in the observed disorganized respiratory pattern.

Cirignotta et $a .^{5}$ have suggested that the frequent desaturations may cause permanent hypoxic damage and contribute to the progressive cerebral deterioration. The influence of anaesthetic agents on respiratory patterns during the perioperative period is not known. A typical history of apnoea was not elicited in our patient. This information must be interpreted with caution as polygraph monitoring has demonstrated breathing impairment in all Rett patients that have been studied ${ }^{5,8}$ Episodes of desaturation have been recorded at a time when parents or nurses reported the child quiet and breathing regularly. ${ }^{5}$ Marked variability between examinations has also been observed. A negative history for apnoea may be unrelia- 
ble. All patients with suspected Rett syndrome should be considered to have a disorder of respiratory control and to experience periods of desaturation.

Preoperative assessment of respiratory function should address the potential for aspiration, respiratory muscle weakness and apnoea. Exercise testing and formal pulmonary function testing are unlikely to be available. Controlled ventilation and perioperative arterial blood gas monitoring is indicated. The patient presented had minimal respiratory symptoms, no evidence of recurrent aspiration and a normal chest $x$-ray. Postoperative control of ventilation was planned until rewarming occurred. It was continued overnight because of ongoing blood loss and minor haemodynamic instability. Supplementary oxygen and saturation monitoring perioperatively appear to be warranted. The requirement for post-surgical admission to the ICU should take into account the severity of symptoms, nature of surgery and anaesthesia.

Cardiovascular considerations of patients with neuromuscular scoliosis have been well described by Kafer. ${ }^{10}$ Vasomotor disturbances leading to cool limbs with tropic changes are seen in $\mathbf{5 0}$ per cent of older affected children. Profuse sweating may also be observed. Unintentional hypothermia occurred in our patient. A thin body habitus, suspension in the Relton-Hall frame and a large exposed evaporative operative surface all contributed to cooling. Aggressive attempts to control heat loss are required.

Metabolic abnormalities have been studied extensively. Elevated ammonia concentrations were reported in Rett's original paper ${ }^{2}$ but are not seen as a consistent feature of the condition. Increased concentrations of lactic acid have also been reported. ${ }^{3}$ Zoghbi et al. " studied the CSF of affected patients specifically to consider the possibility of an abnormality in neurotransmitter function. Dopamine serves as a synaptic transmitter in the basal ganglia which are involved with the control of movement. Seritonin and norepinephrine have a role in sleep-wake cycles and control of autonomic systems. The function of these neurotransmitters can be indirectly assessed by quantitative analysis of their metabolites in the CSF. Zoghbi ${ }^{11}$ has reported a reduction in dopamine and norepinephrine metabolites in six patients studied. Defficiency of the enzyme tyrosine hydroxylase could account for the reduced levels of neurotransmitter metabolites.

A normal anion gap metabolic acidosis developed postoperatively. Although patients with this syndrome have been reported to develop lactic acidosis, the acidosis in our patient could be attributed to rapid IV fluid administration.

\section{Summary}

Rett syndrome is a recently recognized neurological disorder of females, typified by dementia, autistic behav- iour, ataxia, loss of use of the hands and an impairment of respiratory control leading to frequent oxygen desaturations. The neurological features of this disorder and the cardiorespiratory manifestations of co-existing problems such as scoliosis, together with a concern for exacerbation of the respiratory defect necessitates careful preoperative assessment. Our patient with Rett syndrome tolerated anaesthesia well; in particular apnoea and oxygen desaturation were not observed. Complications common to this type of surgery such as blood loss, hypothermia and metabolic acidosis were encountered. Careful anaesthetic techniques regarding positioning, temperature loss, fluid management and observation of respiratory function are required to avoid potential complications. Awareness of this syndrome is important since similar patients might be encountered with increasing frequency for incidental or corrective surgery. The anaesthetist is in a position to contribute to the further experience necessary to determine if these patients are at increased risk during the perioperative period.

\section{References}

1 Al-Mateen M, Philippart M, Shields WD. Rett syndrome: a commonly overlooked progressive encephalopathy in girls. Am J Dis Child 1986; 140: 761-5.

2 Rett $A$. Ueber ein eigenartiges himatropisches Syndrome bei Hyperammonamie im Kindersalter. Wien Med Wochenschr 1966; 116: 723-38.

3 Hagberg B, Aicardi J, Dias $K$, Ramos O. A progressive syndrome of autism, dementia, ataxia and loss of purposeful hand use in girls: Rett's syndrome: Report of 35 Cases. Ann Neurol 1984; 14: 471-9.

4 Hagberg $B$. Rett's syndrome: prevalence and impact on progressive severe mental retardation in girls. Acta Paediatr Scand $1985 ; 74: 405-8$.

5 Cirignotta $F$, Lugaresi $E$, Montagna $P$. Breathing impairment in Rett syndrome. Am J Med Genet 1986; 24 Suppl I: 167-73.

6 Wesecky, A. Music therapy for children with Rett syndrome. Am J Med Genet 1986; 24 Supp J: 253-7.

7 Miller RD. Anesthesia, 2nd ed. New York: Churchill Livingstone, 1986: 920.

8 Glaze DG, Frost $J D J r$., Zoghbi HY, Percy AK. Ren's syndrome: characterization of respiratory patterns and sleep. Ann Neurol 1987; 21 : 377-82.

9 Lugaresi E. Cirignotta $F$, Montagna $P$. Breathing in the Rett syndrome. Brain Dev 1985; 7: 329-33.

$10 \mathrm{Kafer} E R$. Respiratory and cardiovascular functions in scoliosis and the principles of anesthetic management. Anesthesiology 1980; 52; 339-51.

11 Zoghbi HY, Percy AK, Glaze DG, Buller IJ, Riccardi $V M$. Reduction of biogenic amine levels in the Rett syndrome. N Engl J Med 1985; 313: 921-4. 
Résumé

Le syndrome de Rett, qui n'atteint que les femmes, se distingue par de la démence, de l'autisme, de l' incoordination musculaire et un contróle anormal de la respiration. Récemment, nous avons fait une anesthésie générale pour arthrodèse vertébrale chez une patiente de 14 ans, victime de ce syndrome. L'hypothermie, les pertes sanguines et l'acidose métabolique encourues ont été dans les limites habituelles de ce genre d'opération. Le contrôle anormal de sa respiration ne s'est pas aggravé lors de l'intervention. 